This item was submitted to Loughborough's Research Repository by the author.

Items in Figshare are protected by copyright, with all rights reserved, unless otherwise indicated.

\title{
Inorganic impact modifier and processing aid for PVC
}

PLEASE CITE THE PUBLISHED VERSION

PUBLISHER

(C) Maney Publishing

VERSION

VoR (Version of Record)

LICENCE

CC BY-NC-ND 4.0

REPOSITORY RECORD

Gilbert, Marianne, David J. Hitt, G. Schmaucks, B. Friede, A. Sorhuus, and J.O. Roszinski. 2009. "Inorganic Impact Modifier and Processing Aid for PVC". figshare. https://hdl.handle.net/2134/4506. 
This item was submitted to Loughborough's Institutional Repository (https://dspace.lboro.ac.uk/) by the author and is made available under the following Creative Commons Licence conditions.

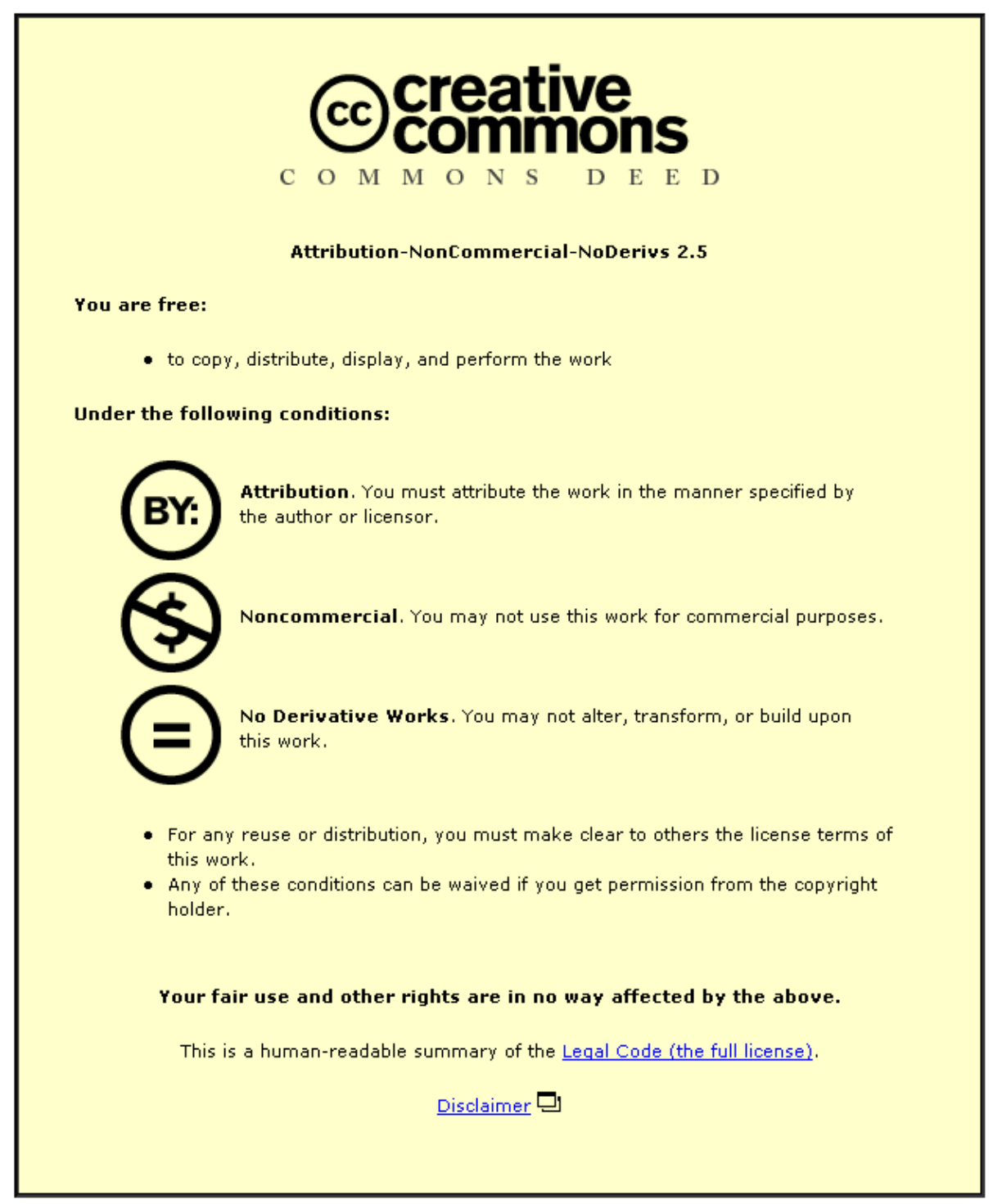

For the full text of this licence, please go to: http://creativecommons.org/licenses/by-nc-nd/2.5/ 


\title{
Inorganic impact modifier and processing aid for PVC
}

\author{
M. Gilbert*1, D. J. Hitt ${ }^{1}$, G. Schmaucks ${ }^{2}$, B. Friede ${ }^{2}$, A. Sørhuus ${ }^{2}$ and \\ J. 0. Roszinski
}

An amorphous silica, SIDISTAR has been investigated as an impact modifier for rigid PVC. Optimal dispersion of the silica as primary particles is essential and this can be achieved by incorporating it at an early stage of the mixing process before other fillers are added. This ensures that the PVC grains are coated with SIDISTAR. This material is able to function as an impact modifier via the cavitation mechanism and it will also improve the dispersion of the other ingredients in the compound. It was found that SIDISTAR delayed gelation of the PVC compound, but this could be avoided by minor changes in formulation and processing conditions. Reduction in gelation time resulted in improved impact performance. Furthermore, compounds containing SIDISTAR possessed a wide processing window.

Keywords: Amorphous silica, Rigid PVC, Impact modification

\section{Introduction}

The general understanding of impact improvement of thermoplastics is that the presence of a second elastomeric - phase is essential to absorb the mechanical energy of the impact stress. In PVC, for instance, this second phase either forms a honeycombed network encapsulating the PVC primary particles, like chlorinated polyethylene (CPE) and ethylene vinylacetate (EVA), or spherical particles with an average size of about $0 \cdot 2 \mu \mathrm{m}$ are evenly dispersed in the thermoplastic matrix, like methyl methacrylate butadiene styrene (MBS) or polyacrylates. ${ }^{1}$

However, it is also known that certain inorganic particles can have a positive influence on impact strength, like nanoclays or fine talc in polypropylene (PP) or ultrafine coated precipitated calcium carbonate in PVC. ${ }^{2}$ The essential property of the second phase is therefore not its chemical nature but rather the size and the shape of the primary particles. An inorganic material based on synthetic amorphous silicon dioxide with an average primary particle size of $150 \mathrm{~nm}$ and a specific surface area of $20 \mathrm{~m}^{2} \mathrm{~g}^{-1}$, called SIDISTAR has recently been developed (Fig 1).

\section{Experimental}

A number of different trials to evaluate the performance of SIDISTAR as an impact modifier (IM) were undertaken. Various compounds based on typical window profile formulations were used (Tables 1-3).

1IPTME, Loughborough University, Loughborough University, Loughborough, LE11 3TU

2Elkem ASA, Materials, Kristiansand, Norway

*Corresponding author, email m.gilbert@lboro.ac.uk

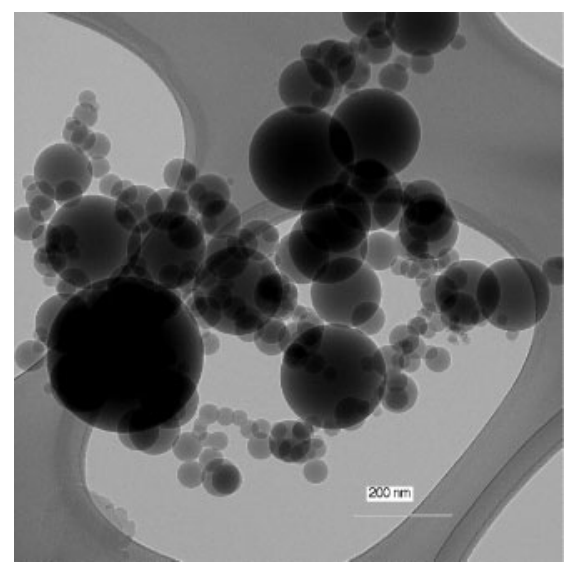

1 Transmission electron micrograph of SIDISTAR primary particles

Dry blending was carried out using both laboratoryscale and industrial-scale high-speed mixers. It was found necessary to mix all ingredients with the exception of calcium carbonate and titanium dioxide first, then add these fillers later in order to ensure that the additives were well dispersed.

In order to investigate the mixing and dispersion process in more detail, a $3-\mathrm{kg}$ batch of the calcium/zinc

Table 1 Formulations of type $\mathrm{A}$ - lead based

\begin{tabular}{lc}
\hline Material & pph \\
\hline PVC resin K68 & 100 \\
Stabiliser/lubricants & $5 \cdot 55$ \\
Calcium stearate & 0.6 \\
Filler & 7 \\
$\mathrm{TiO}_{2}$ & 4 \\
SIDISTAR or acrylic modifier & 8 \\
\hline
\end{tabular}




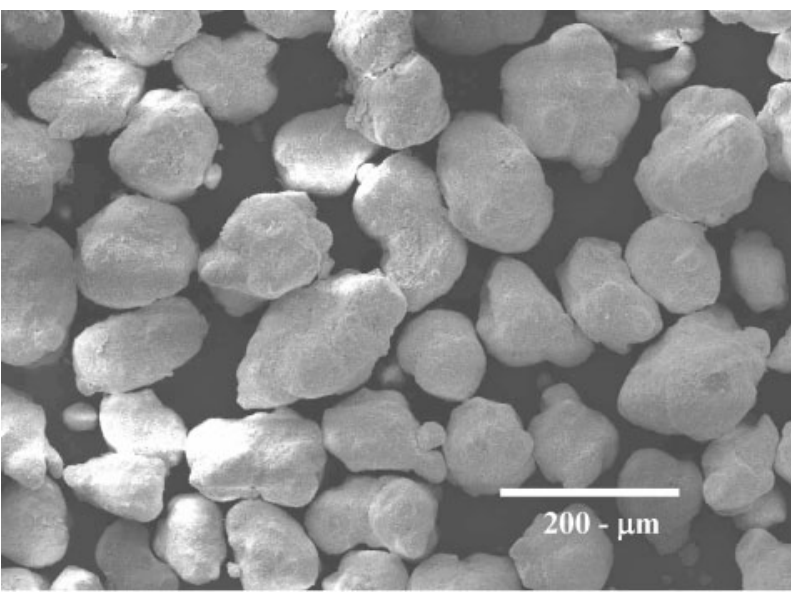

2 Array of PVC particles after mixing for $4 \mathrm{~min}$

based formulation type $\mathrm{B}$ was mixed in an $8 \mathrm{~L}$ TK Fielder mixer. All materials except calcium carbonate and titanium dioxide were loaded into the preheated $\left(80^{\circ} \mathrm{C}\right)$ mixing chamber and stirred at $2000 \mathrm{rev} \mathrm{m}^{-1}$ to $100^{\circ} \mathrm{C}$. After $6 \mathrm{~min}$, the motor was stopped and the filler and pigment were added. Mixing was resumed at $2000 \mathrm{rpm}$ and continued until the temperature reached $120^{\circ} \mathrm{C}$ (a total of $14 \mathrm{~min}$ ). During this mixing experiment, mix samples were extracted every $2 \mathrm{~min}$, and examined using a Leo S360 scanning electron microscope with energy dispersive x-ray analysis.

For some formulations, a Haake Rheocord Polylab torque rheometer was used to investigate the gelation process. The dry blend ( $60 \mathrm{~g})$ was mixed at a rotor speed of $40 \mathrm{rev} \mathrm{m}^{-1}$ at $190^{\circ} \mathrm{C}$.

Laboratory-scale extrusion was carried out using a Krauss Maffei KMD L25 extruder with a $30 \times 5 \mathrm{~mm}$ slot die.

Samples from extrudates for mechanical testing were prepared by routing out appropriate specimens. Tensile testing was performed using a Hounsfield tensometer with a grip separation speed of $10 \mathrm{~mm} \mathrm{~min}{ }^{-1}$. Impact testing was carried out using both unnotched specimens at $0^{\circ} \mathrm{C}$ (unnotched Charpy according to ISO $179 / 1 \mathrm{eU}$ ) and notched samples (BS EN ISO 179:1997) at room temperature.

A Du Pont Differential Scanning Calorimeter (DSC) was used to determine the degree of fusion of samples of extruded PVC and its maximum processing temperature. ${ }^{3}$ Extrudate samples of about $10 \mathrm{mg}$ were compacted in

Table 2 Formulations of type B - calcium/zinc based (pph)

\begin{tabular}{|c|c|c|c|c|c|c|c|c|}
\hline & CZ 0 & CZ 1 & CZ 2 & CZ $3 \mathrm{C}$ & CZ 4 C & CZ 5 & CZ $6 \mathrm{C}$ & CZ 7 \\
\hline PVC & $100 \cdot 0$ & $100 \cdot 01$ & $100 \cdot 0$ & $100 \cdot 01$ & $100 \cdot 01$ & $100 \cdot 01$ & $100 \cdot 01$ & $100 \cdot 0$ \\
\hline $\begin{array}{l}\mathrm{Ca} / \mathrm{Zn} \\
\quad \text { stabiliser }\end{array}$ & $4 \cdot 0$ & $4 \cdot 0$ & $4 \cdot 0$ & $4 \cdot 0$ & $4 \cdot 0$ & $4 \cdot 0$ & $4 \cdot 0$ & $4 \cdot 0$ \\
\hline Lubricants & 0.4 & 0.4 & 0.4 & 0.4 & 0.4 & 0.4 & 0.4 & 0.4 \\
\hline $\mathrm{CaCO}_{3}$ & $5 \cdot 0$ & $5 \cdot 0$ & $5 \cdot 0$ & $5 \cdot 0$ & $5 \cdot 0$ & $5 \cdot 0$ & $5 \cdot 0$ & $5 \cdot 0$ \\
\hline $\mathrm{TiO}_{2}$ & $3 \cdot 0$ & $3 \cdot 0$ & $3 \cdot 0$ & $3 \cdot 0$ & $3 \cdot 0$ & $3 \cdot 0$ & $3 \cdot 0$ & $3 \cdot 0$ \\
\hline $\begin{array}{l}\text { Processing } \\
\text { aid }\end{array}$ & $1 \cdot 0$ & $1 \cdot 0$ & $1 \cdot 0$ & $1 \cdot 0$ & $1 \cdot 0$ & $1 \cdot 0$ & $1 \cdot 0$ & $1 \cdot 0$ \\
\hline $\begin{array}{l}\text { Acrylic } \\
\text { modifier }\end{array}$ & - & $8 \cdot 0-$ & & - & $4 \cdot 0$ & $4 \cdot 0-$ & & $2 \cdot 0$ \\
\hline Tyrin 7000 & - & - & $8.0-$ & & $4 \cdot 0-$ & & $4 \cdot 0-$ & \\
\hline SIDISTAR & - & - & - & $8 \cdot 0-$ & & $4 \cdot 0$ & $4 \cdot 0$ & $6 \cdot 0$ \\
\hline
\end{tabular}

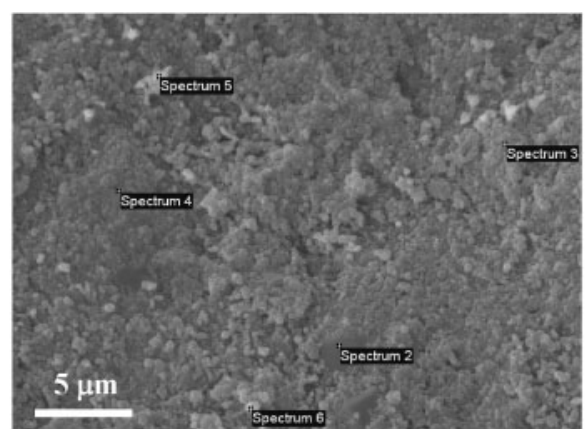

(a)

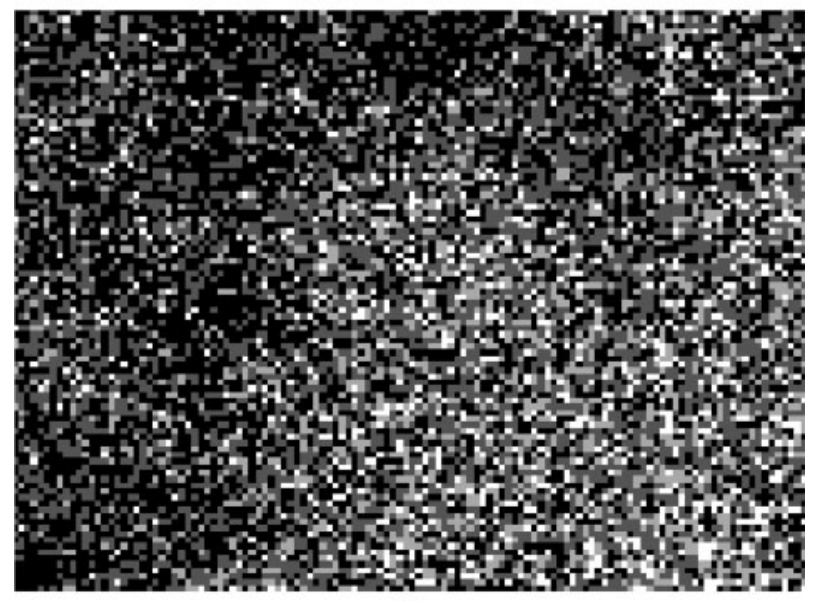

(b)

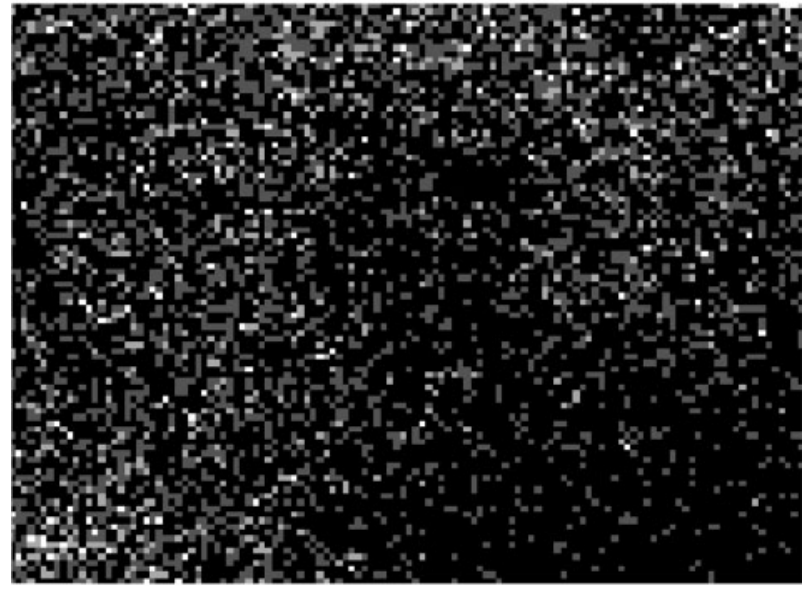

(c)

3 Surface of a PVC grain after mixing for $4 \mathrm{~min}$ a SEM micrograph; $b$ Si map; $c$ Cl map

Table 3 Formulations of type $\mathrm{C}-$ calcium/zinc based with one pack of lubricant/stabiliser (pph)

\begin{tabular}{lccc}
\hline & $\begin{array}{l}\text { CZ0B } \\
\text { (no modifier) }\end{array}$ & $\begin{array}{l}\text { CZ1B } \\
\text { (acrylic } \\
\text { modifier) }\end{array}$ & $\begin{array}{l}\text { CZ3B } \\
\text { (SIDISTAR) }\end{array}$ \\
\hline PVC resin K68 & 100.0 & 100.0 & 100.0 \\
Stabiliser/lubricant & 4.5 & 4.5 & 4.5 \\
$\quad$ one-pack & & & \\
Process aid & 1.0 & 1.0 & 1.0 \\
Filler & 5.0 & 5.0 & 5.0 \\
TiO 2 & 3.0 & 3.0 & 3.0 \\
Impact modifier/ & & 8.0 & 8.0 \\
$\quad$ SIDISTAR & & &
\end{tabular}




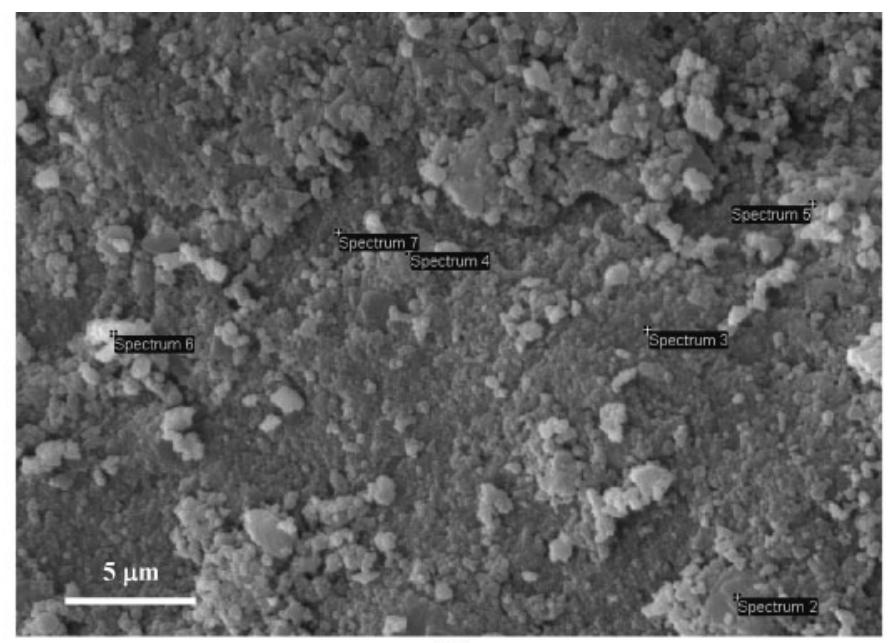

(a)

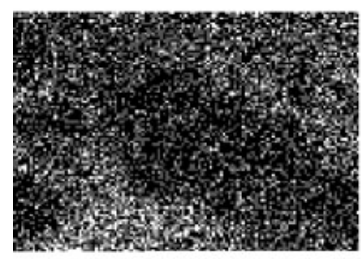

(b)

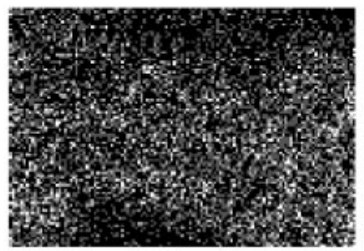

(c)

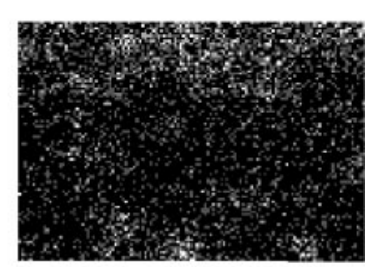

(d)

4 Surface of a PVC grain after mixing for 10 min a SEM micrograph; $b$ Si map; $c$ Cl map; $d$ Ca map

aluminium pans, and sealed. The samples were run at a heating rate of $20^{\circ} \mathrm{C} \mathrm{min}^{-1}$ in nitrogen.

\section{Results}

Figure 2 shows an SEM micrograph of the PVC compound after mixing for $4 \mathrm{~min}$. All additives present at this stage appear to be coated onto the PVC particles. Elemental maps of the surface of one of these particles (Fig. 3) shows that silica particles are distributed on the grain surface, although not entirely uniformly; the bottom right hand area is rich in silicon (Fig. 3b), while the top left hand area is rich in chlorine, implying little coverage. Spot analysis for elements was carried out in regions labelled spectrum 2-6 in Fig. $3 a$; silicon was detected in all cases, but varied in concentration from 15 to $48 \%$. The spherical particle analysed in spectrum 6 was mainly silica, while the irregular particle (spectrum 5) had the lowest silicon content, but was relatively rich in oxygen, indicating that it was possibly associated with the processing aid present. Calcium carbonate and $\mathrm{TiO}_{2}$ were added after $6 \mathrm{~min}$. Results after mixing for $10 \mathrm{~min}$ are shown in Fig. 4 and Table 4. Again, elemental maps show that there are regions of concentration variation for the additives being investigated. Larger additive particles are visible, particularly $\mathrm{CaCO}_{3}$ (e.g. spectrum 2). The amount of silica present is clearly lower than that

Table 4 Elemental analysis of the surface of a PVC grain after mixing for $10 \mathrm{~min}$

\begin{tabular}{lllrrrr}
\hline $\begin{array}{l}\text { Spectrum } \\
\text { no. }\end{array}$ & C & O & \multicolumn{1}{l}{$\mathbf{S i}$} & \multicolumn{1}{c}{$\mathbf{C l}$} & \multicolumn{1}{l}{$\mathbf{C a}$} & $\mathbf{T i}$ \\
\hline 2 & & $52 \cdot 71$ & $8 \cdot 93$ & $5 \cdot 88$ & $32 \cdot 49$ & \\
3 & $42 \cdot 73$ & $29 \cdot 56$ & $8 \cdot 44$ & $12 \cdot 85$ & & $6 \cdot 43$ \\
4 & $25 \cdot 97$ & $46 \cdot 69$ & $5 \cdot 91$ & $5 \cdot 44$ & $9 \cdot 43$ & $6 \cdot 55$ \\
5 & $16 \cdot 37$ & $45 \cdot 82$ & $15 \cdot 21$ & $7 \cdot 22$ & $5 \cdot 51$ & $9 \cdot 87$ \\
6 & $29 \cdot 17$ & $36 \cdot 61$ & $12 \cdot 00$ & $6 \cdot 63$ & $4 \cdot 95$ & $10 \cdot 65$ \\
7 & & $50 \cdot 39$ & $23 \cdot 31$ & $26 \cdot 30$ & & \\
\hline
\end{tabular}

shown in Fig. 3, confirming that the $\mathrm{CaCO}_{3}$ and $\mathrm{TiO}_{2}$ have formed a coating over the silica. $\mathrm{TiO}_{2}$ which has a particle size of around $1 \mu \mathrm{m}$, is detectable in most spectra, implying that it is reasonably well dispersed. Fig. 5 shows PVC grains at the end of the mixing process. It is clear that additives have filled in undulations on the grain surfaces, making all grains much smoother.

In a typical profile formulation (Table 1), SIDISTAR increases the impact strength compared with the unmodified control by almost $70 \%$ at $0^{\circ} \mathrm{C}$ (Fig. 6). However, the acrylic IM performs significantly better. More impressive is the result in a 50:50 blend of SIDISTAR with conventional acrylic IM. In this case, the measured impact strength reaches more than three times that of the control and exceeds even the result of the acrylic IM on its own (Fig. 7). This can probably be explained by its effectiveness in improving the dispersion of the other compound ingredients, e.g. the acrylic IM,

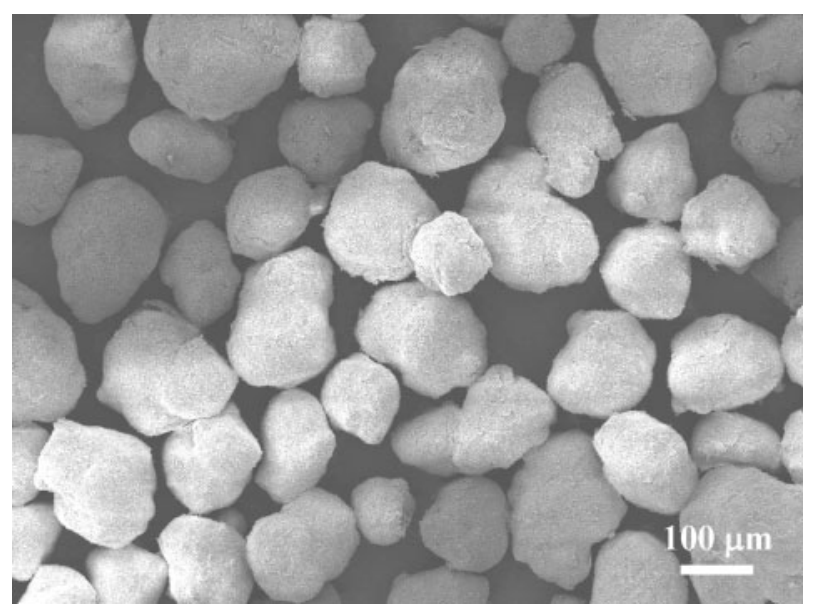

5 Array of PVC particles at end of mixing 


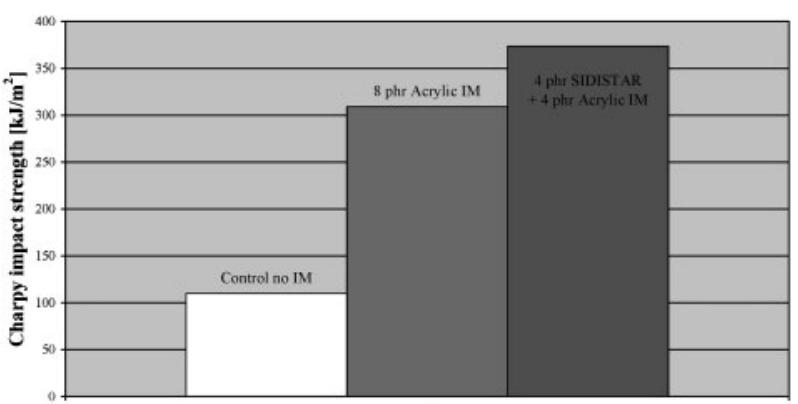

6 Unnotched impact strengths for formulations based on A - complete replacement of acrylic IM with SIDISTAR

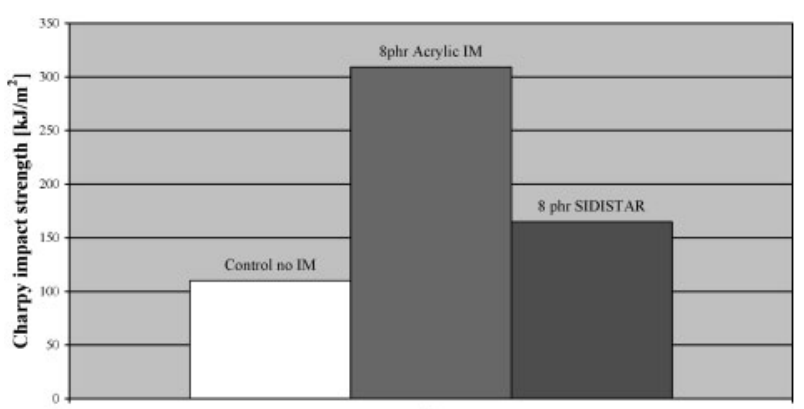

7 Unnotched impact strengths for formulations based on A - 50\% replacement of acrylic IM with SIDISTAR

making them more effective, as seen in Fig. 8. It is believed that when the spherical SIDISTAR particles are well dispersed throughout the polymer matrix, they will dissipate the impact energy over their particle surface so that in any direction the transmitted energy value is smaller than necessary for crack initiation or propagation. TEM (transmission electron microscopy) investigations prove that on impact the particles create a space between themselves and the surrounding polymer matrix (Fig 9) thus avoiding energy transmittance. This has been described as the cavitation mechanism.

When evaluating the reason for the different behaviour of SIDISTAR either alone or in combination with acrylic IM, it was found that there is a strong influence

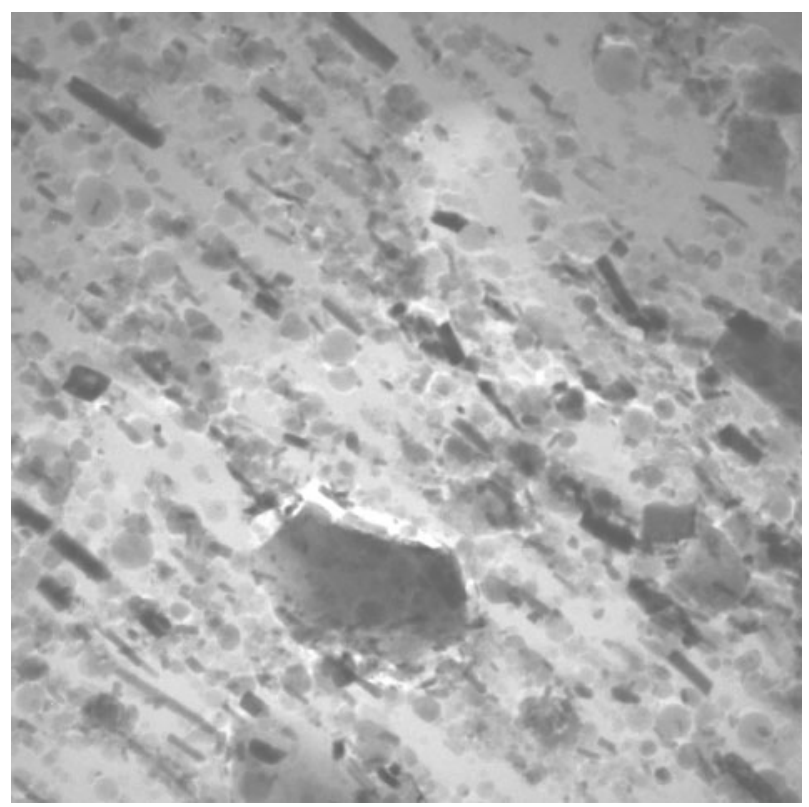

9 Cavitation after impact - sample containing 8pph SIDISTAR

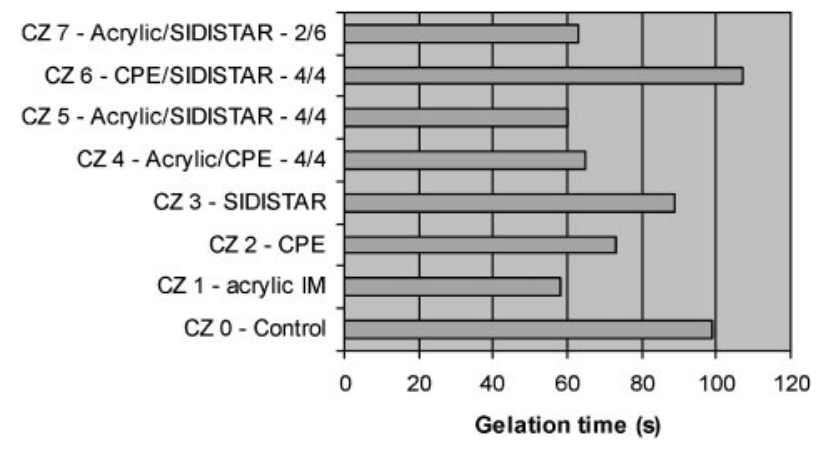

10 Gelation times for $\mathrm{Ca} / \mathrm{Zn}$-stabilised compounds

of the inorganic material on the gelation time of the PVC compound as measured using a Haake Rheocord for formulations shown in Table 2. The results are shown in Fig. 10. It was therefore concluded that the formulation containing SIDISTAR should be optimised

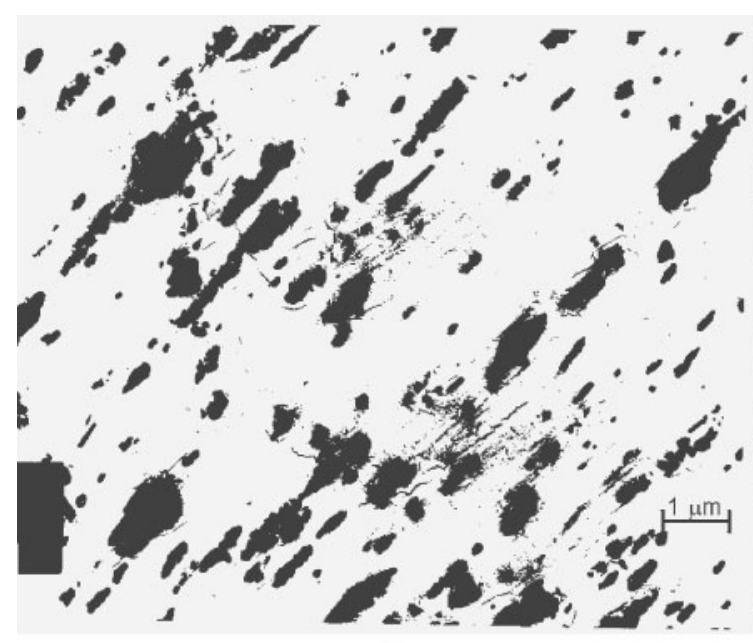

(a)

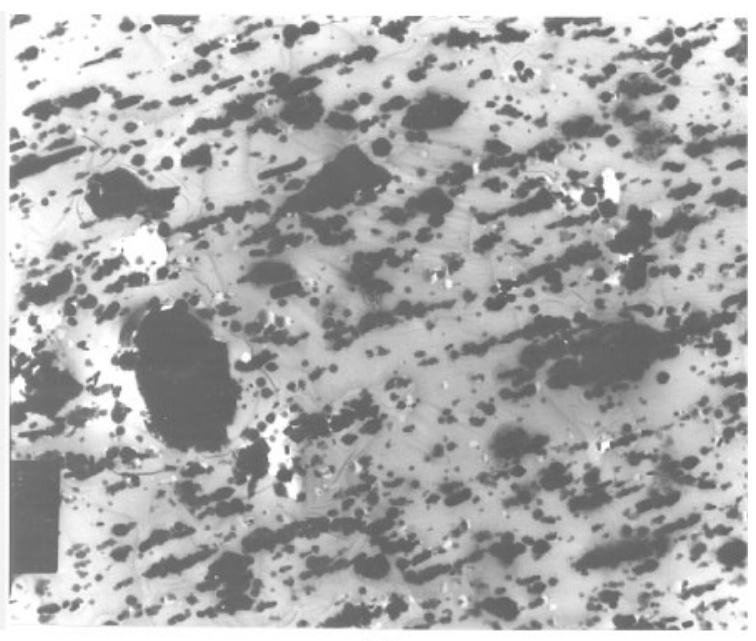

(b)

8 TEM photographs showing a strong orientation of compound ingredients in profile containing no SIDISTAR and $b$ improved dispersion and reduced orientation due to addition of 8 pph SIDISTAR 


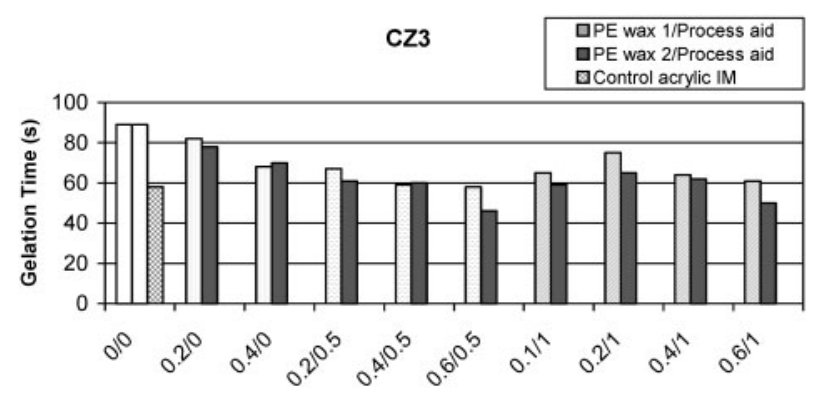

PE Wax / Process Aid

11 Gelation time of optimised SIDISTAR formulation CZ3

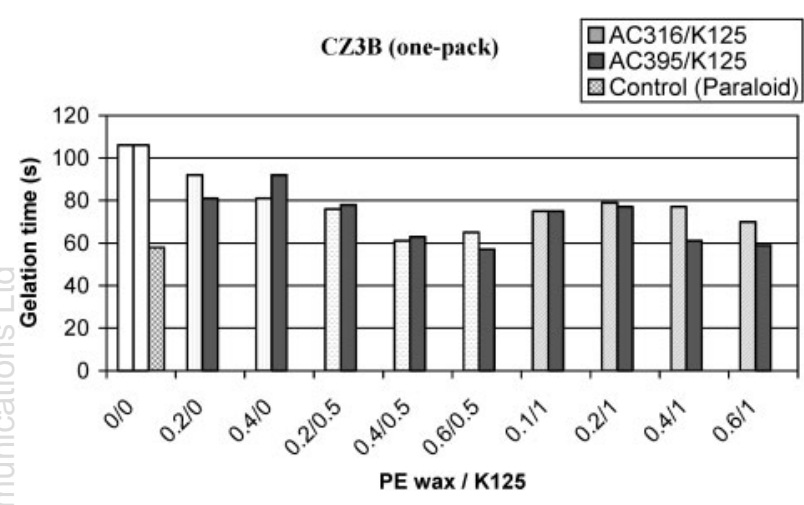

12 Gelation time of optimised SIDISTAR formulation CZ3B

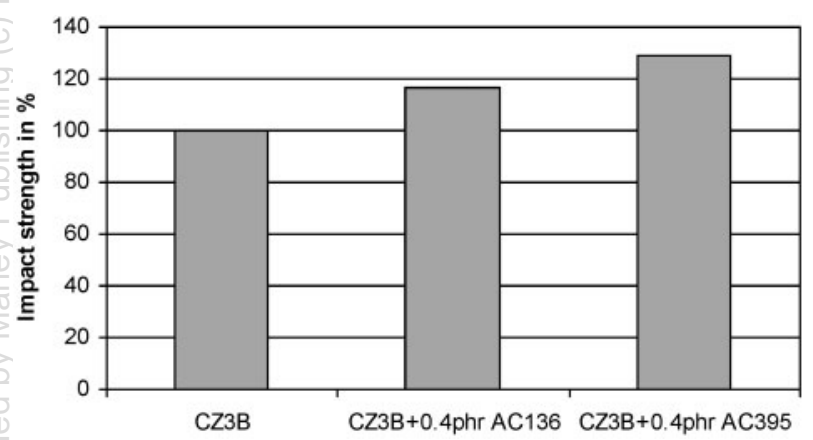

13 Impact strength of optimised $\mathrm{Ca} / \mathrm{Zn}$-stabilised PVC formulations

to have similar gelation times to those containing other impact modifiers. To investigate possible routes for reducing gelation time for formulations containing SIDISTAR, an external lubricant, oxidised PE wax, and a processing aid were added to formulation CZ3, and Type $\mathrm{C}$ formulations containing a one-pack stabiliser/ lubricant system. Concentrations of the oxidised PE wax and process aid were varied between 0 and $1.0 \mathrm{pph}$, for the process aid, and $0 \cdot 1$ and $0 \cdot 6 \mathrm{pph}$ for the oxidised PE wax. Two different PE waxes were chosen with acid numbers of 16 and 30, respectively. The results are shown in Figs 11 and 12. It is seen that gelation time can be varied considerably by the modifications shown for compounds containing separate stabiliser and lubricant or for those based on a one-pack system, thus providing a method of optimising gelation time as well as mechanical properties.

Test samples were produced for the formulation based on CZ3B with 0.4 pph of each of the oxidised PE wax

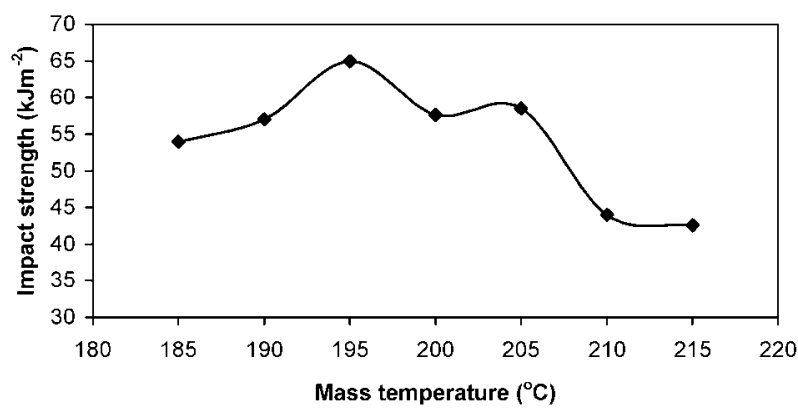

14 Effect of processing temperature on impact strength for lead-based formulation

samples. The impact strength of these modified formulations is shown in Fig. 13. Reduced gelation time has also increased impact strength for both formulations of type B and C. It is believed that further optimisation of both gelation time and mechanical properties remains possible.

For rigid PVC, an increase in processing temperature increases the degree of gelation, while impact strength tends to pass through a maximum at a gelation level of $60-80 \%$. ${ }^{4,5}$ Earlier experiments have shown that compounds modified by the addition of SIDISTAR have a wide processing window, i.e. fusion level and impact properties are not particularly dependent on processing temperature. Impact strength (unnotched Charpy) is plotted as a function of mass temperature for a leadstabilised compound (Type A) in Fig. 14. It is seen that reasonable levels of impact strength are obtained across a mass temperature range of $185-205^{\circ} \mathrm{C}$. For compound CZ3B, DSC was used to estimate actual processing temperature and fusion level using the method described previously ${ }^{3}$. The enthalpy corresponding to endotherm $\mathrm{A}\left(\Delta H_{\mathrm{A}}\right)$ is a measure of fusion of the PVC grains and can range from 0 to about $10-12 \mathrm{~J} \mathrm{~g}^{-1}$. Results in Table 5 show consistent levels of fusion for compound CZ3B over the temperature range investigated; the values themselves being similar to that for an acrylic modified compound CZ1B. SIDISTAR also reduces the internal friction due to the spherical shape of the primary particles. Large-scale extrusion trials revealed that output can be increased due to the improved melt flow.

\section{Conclusions}

To achieve all the benefits SIDISTAR can provide, optimal dispersion as primary particles is essential. This can be achieved by incorporating it before the filler is added at an early stage of the mixing process, to ensure that the PVC grains are coated with SIDISTAR. It functions as an impact modifier via the cavitation

Table 5 DSC results for Type C compounds

\begin{tabular}{llll}
\hline & $\begin{array}{l}\text { Measured } \\
\text { processing } \\
\text { temperature, }\end{array}$ & $\begin{array}{l}\text { Actual (DSC) } \\
\text { processing } \\
\text { temperature, }\end{array}$ & \\
Compound & ${ }^{\circ} \mathbf{C}$ & ${ }^{\circ}$ C & $\Delta H_{\mathrm{A}}, \mathbf{J ~ g ~}^{-\mathbf{1}}$ \\
\hline CZ3B & 190 & 188 & $5 \cdot 9$ \\
CZ3B & 195 & 193 & $5 \cdot 4$ \\
CZ3B & 200 & 196 & $5 \cdot 6$ \\
CZ1B & 200 & 194 & $5 \cdot 8$ \\
\hline
\end{tabular}


mechanism and also improves the dispersion of the other compound ingredients. It was found that SIDISTAR delayed gelation of the PVC compound, but this could be avoided by minor changes in formulation and processing conditions. Reduction in gelation time resulted in improved impact performance. Furthermore, it was found that compounds containing SIDISTAR possessed a wide processing window.

\section{Acknowledgements}

Thanks are due to $\mathrm{Mr}$ Bernd Kretzschmar of the Institute of Polymer Research, Dresden, Germany who produced impact data over a range of processing temperatures. Based on a presentation at the 9th International PVC Conference held in Brighton, UK, in April 2005.

\section{References}

1. R Gächter and H. Müller: Plastics additives handbook, Hanser Publications, 1996, pp 506.

2. D. W. Cornwell: Industrial minerals, July 2001, 35-37.

3. M. Gilbert, D. A. Hemsley and A. Miadonye: Plast Rubber Process. Appl., 1983, 3, 343-351.

4. J. A. Covas, M. Gilbert and D. E. Marshall: Plast. Rubber Process. Appl., 1988, 9, 107-116.

5. D. E. Marshall, R. P. Higgs and O. P. Obande: Plast. Rubber Process. Appl., 1983, 3, 353-358. 